\title{
Market Analysis on Civil Aviation of China After Joining Aviation Alliance
}

\author{
Jianhui Wang \\ Transportation Management College of Civil Aviation \\ Flight University of China (CAFUC) \\ Guanghan, China \\ atcerwjh@126.com
}

\author{
Jianguo Kong \\ Transportation Management College of Civil Aviation \\ Flight University of China (CAFUC) \\ Guanghan, China
}

\author{
Yuran Zhu \\ Southwest Regional Air Traffic Management Bureau (ATMB) of CAAC \\ Chengdu, China
}

\begin{abstract}
With China Eastern joined Sky Team Alliance in 2011, the three biggest state-owned airlines in China have all joined aviation alliance. After joining aviation alliance, both the domestic and international markets of China's civil aviation company will change. This paper studies the domestic and international change separately, first use grey prediction method to predict the future domestic transportation target and fleet scale, meanwhile evaluate domestic market change by taking code sharing and China's civil aviation layout into consideration. While evaluating international market, use population mutual competition model to predict international market share variation tendency in aviation alliance, and use the Shapley value on the market share for equitable distribution. Finally get the international market share change, thus to provide theoretical reference to civil aviation of China joining aviation alliance.
\end{abstract}

Keywords-aviation alliance; grey prediction; code sharing; market share; shapley value

\section{FOREWORD}

Since the Northwest airlines and KLM Royal Dutch airlines to jointly opening up the aviation alliance in 1989, now there have formed three aviation alliances, they are: Star alliance, One World, and Sky Team alliance. Till the end of 2010, the number of airlines joining these alliances is more than 50, whose passenger load per year accounts for $60 \%$ in the global aviation load, while the income was $65.7 \%$. Experts predict that with the growing trend of airline alliances, the number of airlines joining alliance will be close to hundred a few years later. The global aviation transportation market share of these alliances will reach $80 \%$. China southern airlines joined Sky Team alliance in 2007, while in the same year Air China, Shanghai airlines joined the Star alliance, and China Eastern airlines joined Sky Team alliance in 2011. Total up Cathay Pacific and Hong Kong which joining One World previously, the majority of China's airlines have joined aviation alliance, and China's fourth biggest airline -Hainan Airlines also plans to join One World. The world's second largest civil aviation market officially became part of the world aviation market.
Join the alliance's essence increases the airline's competitive ability and profit, however, from 2007 to the present, China southern airlines, the first one joining aviation alliance, didn't get any obvious benefits, and the target of improved international routes income from the current $17 \%$ to $30 \%$ is unrealized. How to get better development in the alliance is related to the survival of civil aviation of China, the development and profits of airlines have close relations with market share. This paper analyzes the market changes after three biggest airlines joining aviation alliance.

\section{DOMESTIC MARKET ANALYSIS OF CIVIL AVIATION OF CHINA}

\section{A. Domestic Market Statistics of Civil Aviation of China}

China's civil aviation industry has always been the focus of the global civil aviation, even in 2008 when the entire civil aviation declined, China's aviation market also maintained an amazing growth. The passenger traffic volume and transportation total turnover volume are the main targets reflecting the civil aviation market demand of an area, while the attendance reflects the relation between supply and demand of civil aviation. The majority of flights in China have maintained the attendance more than eighty percent; some even exceeds more than ninety percent. In all, the attendance higher than $70 \%$ of international civil aviation can be called normal attendance. That is, by international standards, the supply and demand of China's domestic civil aviation is oversupply. As China's civil aviation passenger plane purchase belongs to government planning, so we can know the relation between supply and demand in the next few years by predicting China's civil aviation transportation total turnover volume and passenger traffic volume. The following table is the transportation total turnover volume (10 billion ton-km) and the passenger traffic volume (100 million people) which China's civil aviation has finished from 2001 to 2010. From the table we can see, China's civil aviation has kept a high speed of development in the lately 10 years. 

CHINA

\begin{tabular}{cccccc}
$\begin{array}{c}\text { Year } \\
\text { target }\end{array}$ & $\mathbf{2 0 0 1}$ & $\mathbf{2 0 0 2}$ & $\mathbf{2 0 0 3}$ & $\mathbf{2 0 0 4}$ & $\mathbf{2 0 0 5}$ \\
$\begin{array}{c}\text { Transportation total } \\
\text { turnover volume }\end{array}$ & 1.41 & 1.64 & 1.97 & 2.30 & 2.61 \\
$\begin{array}{c}\text { Passenger traffic } \\
\text { volume } \\
\text { Year }\end{array}$ & 0.75 & 0.86 & 1.04 & 1.21 & 1.38 \\
$\begin{array}{c}\text { target } \\
\text { Transportation total } \\
\text { turnover volume } \\
\text { Passenger traffic } \\
\text { volume }\end{array}$ & 2006 & 2007 & 2008 & $\mathbf{2 0 0 9}$ & $\mathbf{2 0 1 0}$ \\
\hline & 1.60 & 1.85 & 1.92 & 2.31 & 2.68 \\
\hline
\end{tabular}

\section{B. Domestic Market Prediction of Civil Aviation of China}

Grey prediction model is a precise prediction used to do medium and long term prediction. Here we use grey prediction model to predict future transportation total turnover volume and passenger traffic volume in China.

For the transportation total turnover volume: $5.38\}$

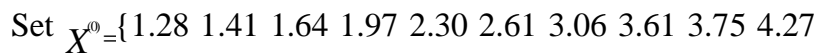

Form accumulation generation sequence:

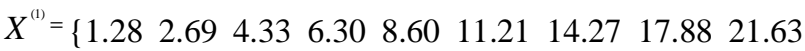
$25.9031 .28\}$

Form data matrix $B$ and data vector $Y$ :

$$
B=\left[\begin{array}{cc}
-1.985 & 1 \\
-3.51 & 1 \\
-5.315 & 1 \\
-7.45 & 1 \\
-9.905 & 1 \\
-12.74 & 1 \\
-16.075 & 1 \\
-19.755 & 1 \\
-23.765 & 1 \\
-28.59 & 1
\end{array}\right] \quad Y=\left[\begin{array}{l}
1.41 \\
1.64 \\
1.97 \\
2.30 \\
2.61 \\
3.06 \\
3.61 \\
3.75 \\
4.27 \\
5.38
\end{array}\right]
$$

$$
\begin{gathered}
\text { Calculate } \hat{a}: \quad B^{T} B=\left[\begin{array}{cc}
2.3913 & -0.1291 \\
-0.1291 & 0.0100
\end{array}\right] \\
\left(B^{T} B\right)^{-1}=\left[\begin{array}{ll}
0.0014 & 0.0178 \\
0.0178 & 0.3299
\end{array}\right] \\
\hat{a}=\left(B^{T} B\right)^{-1} B^{T} Y=\left[\begin{array}{c}
-0.1395 \\
1.1989
\end{array}\right]
\end{gathered}
$$$$
\text { Then } a=-0.1395, b=1.1989
$$

Reach a prediction model:

$$
X_{\wedge}^{1}(k+1)=\left(X^{(0)}(1)-\frac{b}{a}\right) e^{-a k}+\frac{b}{a}=9.8743 e^{0.1395 k}-8.5943
$$

Value $k=10: 1: 15$, execute the procedure:

$$
y=\begin{array}{llll}
31.2482 & 37.2126 & 44.0699 & 51.9536 \\
61.0176 & 71.4384 & &
\end{array}
$$

The same for the passenger traffic volume, the prediction model is:

$$
\begin{aligned}
& Y_{\wedge}^{1}(k+1)=5.4866 e^{0.1347 k}-4.8166 \\
& \text { Value } k=10: 1: 15 \text {, execute the procedure: } \\
& y=16.2842 \quad 19.3267 \quad 22.808126 .7914 \\
& 31.3490 \quad 36.5639
\end{aligned}
$$

The prediction of transportation total turnover volume (10 billion ton-km) and passenger traffic volume (100 million people) which China's civil aviation can be finished in the next five years:

TABLE II. THE PREDICTION OF CHINA'S CIVIL AVIATION TRAFFIC STATISTICS IN THE NEXT FIVE YEARS

$\begin{array}{cccccc}\begin{array}{c}\text { Year } \\ \text { target }\end{array} & 2011 & \mathbf{2 0 1 2} & \mathbf{2 0 1 3} & \mathbf{2 0 1 4} & \mathbf{2 0 1 5} \\ \begin{array}{c}\text { Transportation total } \\ \text { turnover volume }\end{array} & 5.96 & 6.86 & 7.88 & 9.06 & 10.41 \\ \begin{array}{c}\text { Passenger traffic } \\ \text { volume }\end{array} & 3.04 & 3.48 & 3.98 & 4.56 & 5.21 \\ & & & & & \end{array}$

\section{Domestic Market Analysis of Civil Aviation of China}

The transportation fleet scale of China's civil aviation reached to 1593 sorties by the end of 2010, which was three times that of in the year 2000. Compared with the data, the number of China's civil aviation transportation growth rate is slightly less than the total transportation turnover, and equals to the passenger traffic volume. Predicted according to the data from 2010 to 2015, China civil aviation transportation total turnover and passenger traffic volume will be doubled. The civil aviation industry expected, in the next 20 years, China's civil aircraft will add 4583 sorties. Suppose input in five years, and then by 2015, China will add 1146 aircrafts, increased by $72 \%$. Although slightly lower than the increment of total transportation turnover and passengers traffic volume, China's civil aviation can still maintain a higher attendance in the future. The core of aviation alliance is code sharing, which is also the main way to join aviation alliance for China's civil aviation. But joining aviation alliance does not mean that foreign airlines can freely operate in Chinese domestic routes. At present, there are quite a few foreign airlines that can operate in domestic routes, such as from Guangzhou to Beijing, there are more than 50 flights every day but only 2 united airlines flights. The main effect of joining aviation alliance to the domestic market is attendance. For example, most of the passengers to China first come to Beijing, Shanghai, and Guangzhou which are the bases of Air China, China Eastern, and China Southern airlines, and then transfer to other places. These passengers will turn to the same code sharing aviation alliance for flight, thus it will further increase the attendance of airlines joining aviation alliance. From 2007, China's domestic airlines began to implement code sharing, and then the arrangement of the domestic flights will be more accorded with the market demand. While the attendance exceeds more than a certain number, the 
airlines' additional cost of carrying more passengers will be greatly reduced, and China's civil aviation domestic market, after joining aviation alliance, will keep a steady growth, meanwhile the attendance will also increase further.

\section{INTERNATIONAL MARKET ANALYSIS OF CIVIL AVIATION OF CHINA}

\section{A. Current Condition of International Market}

Since joining Sky Team alliance in 2007, the international routes income of China southern airlines have been wandering around $20 \%$, far behind the goal of $30 \%$. Other alliance airlines in China are also not optimistic about the international routes income, thus the operation on international route is a key to whether China's civil aviation could survive in the competitive civil aviation market. The international routes incomes of China increase mainly relies on cost reduction, code sharing and flight increase. After joining aviation alliance, China's aircraft can share overseas infrastructure, the centralized purchase can reduce purchase price and expenditure, the special division of routes can make alliance airlines complement each others' advantages, and the code sharing can provide convenient transferring service for the departure passenger. Yet all of these depend on airlines' own strength, that is flying more international routes or more flights on the same route, and meanwhile keep a high attendance, and then the airlines are able to share the welfare of the aviation alliance. In all, the market share is the most important.

\section{B. Market Distribution Prediction of International Routes}

The extra traffic volume and revenue, which aviation alliance airlines achieved in the course competition, come from the non-shared company or other alliances. An alliance airline has a strong competitive advantage on route, but some do not. From the competition view, no matter what kind of situation, international routes market distribution will have a big change. The following use of population mutual competition model is to illustrate the market share change after airlines joining aviation alliance. Here consider the alliance airline on one route having advantage in competition, so does the actual situation.

Set the joining alliance airlines as a group, and the nonjoining airlines as another group. $x_{1}(t)$ is the market share of joining airlines, and $x_{2}(t)$ is the market share of non-joining. $r_{1}, \quad r_{2}$ are inherent growth rate, and $N_{1}, N_{2}$ are their maximum market share. Consider the joining alliance airlines separately:

$$
x_{1}(t)=r_{1} x_{1}\left(1-\frac{x_{1}}{N_{1}}\right)
$$

Divisor $\left(1-\frac{x_{1}}{N_{1}}\right)$ reflects the market share increase of joining airlines is obstructive to its own market share improvement.

While the non-joining airlines exist, we can minus one part from $\left(1-\frac{x_{1}}{N_{1}}\right)$, which is proportion to the market share $x_{2}(t)$.
Then we can get a market share increase equation of joining alliance airlines:

$$
x_{1}(t)=r_{1} x_{1}\left(1-\frac{x_{1}}{N_{1}}-\sigma_{1} \frac{x_{2}}{N_{2}}\right)
$$

$\sigma_{1}$ means under the same cost, the market share of nonjoining alliance airlines is $\sigma_{1}$ times that of joining airlines. While $\sigma_{1}<1$, it means under the same cost, the market share of non-joining alliance airlines is lower than that of joining airlines.

The same, the existing of joining airlines do not influence the market share of non-joining ones, then the market share increase equation of non-joining alliance airlines is:

$$
x_{2}(t)=r_{2} x_{2}\left(1-\frac{x_{2}}{N_{2}}-\sigma_{2} \frac{x_{1}}{N_{1}}\right)
$$

Among this, $x_{1}(t)+x_{2}(t)=1$

For calculating conveniently, suppose the retardation for market share increase to their own market share improvement of both joining and non-joining airlines is the same, then:

$\sigma_{1} \sigma_{2}=1$

While $\mathrm{t}$ increase, $x_{1}(t), x_{2}(t)$ will tend to be stable. Then analyze its stability:

Solve algebra equation set using $x_{1}(t), x_{2}(t)$

$$
\left\{\begin{array}{l}
f\left(x_{1}, x_{2}\right)=r_{1} x_{1}\left(1-\frac{x_{1}}{N_{1}}-\sigma_{1} \frac{x_{2}}{N_{2}}\right)=0 \\
g\left(x_{1}, x_{2}\right)=r_{2} x_{2}\left(1-\frac{x_{2}}{N_{2}}-\sigma_{2} \frac{x_{1}}{N_{1}}\right)=0
\end{array}\right.
$$

Get four equilibrium points:

$$
P_{1}\left(N_{1}, 0\right), \quad P_{2}\left(0, N_{2}\right), P_{3}(0,0), \quad P_{4}\left(\frac{N_{1}\left(1-\sigma_{1}\right)}{1-\sigma_{1} \sigma_{2}}, \frac{N_{2}\left(1-\sigma_{2}\right)}{1-\sigma_{1} \sigma_{2}}\right)
$$

Decide the equilibrium point's stability: as $\sigma_{1} \sigma_{2}=1$, and $\sigma_{1}>0, \sigma_{2}>0$, so the equilibrium points fits the stability conditions are ${ }_{P_{1}}\left(N_{1}, 0\right), P_{2}\left(0, N_{2}\right)$. And the stability condition of $P_{1}{ }^{\text {is }} \sigma_{1}<1, \sigma_{2}>1$, while $P_{2}$ is $\sigma_{1}>1, \sigma_{2}<1$. Input the same cost, the market share of non-joining alliance airlines is lower than that of joining airlines, so $\sigma_{1}<1$, the joining airlines is prior to non-joining ones in the market share competition. $x_{1}(t)$, $x_{2}(t)$ will finally tend to the equilibrium point $P_{1}\left(N_{1}, 0\right)$, then the non-joining airlines would lose their market share. The joining airlines show a gradually increase while the non-joining ones show a decrease.

\section{Market Distribution of International Routes}

From above we can know, the market share of aviation alliance which is dominant on the route competition will increase gradually, and then distributing the additional share reasonably is an important condition for stable development of 
aviation alliance. Most of the alliances are based on interest, if the alliance wants to get fast development, it need to balance each airline's contribution, risks and benefits from the alliance. In general, the aviation alliance distribution of interests obeys the following principles: 1 mutual benefit; 2 the optimal structure interests; 3 risk compensation; 4 individual reasonable; 5 groups reasonable. Many scholars have proofed Shapley value has fair and rational advantages on dealing with distribution problems. Here illustrate the distribution of route market in aviation alliance with the example of route from Hong Kong to Tokyo. The table below is the flight classes from Hong Kong to Tokyo:

TABLE III. THE FLIGHT CLASSES FROM HONG KONG TO TOKYO

\begin{tabular}{clccc} 
& \multicolumn{3}{c}{ Member of One World } & $\begin{array}{c}\text { Other } \\
\text { flights }\end{array}$ \\
Airlines & $\begin{array}{c}\text { Cathay } \\
\text { Pacific }\end{array}$ & $\begin{array}{c}\text { Japan } \\
\text { Airlines }\end{array}$ & $\begin{array}{c}\text { Dragon } \\
\text { Airlines }\end{array}$ & $\begin{array}{c}\text { Other } \\
\text { airlines }\end{array}$ \\
$\begin{array}{c}\text { Flight quantity } \\
\text { Market share }\end{array}$ & 8 & 6 & 1 & 9 \\
Total & $33.3 \%$ & $25 \%$ & $4.2 \%$ & $37.5 \%$ \\
& & $62.5 \%$ & & $37.5 \%$
\end{tabular}

From the table we can see, the market share of One World is nearly two-thirds. As One World includes Cathay Pacific, Japan airlines and Dragon airlines, these airlines can share airport infrastructure in Hong Kong and Tokyo airports and can provide more convenient transfer service. Thus make them more competitive over other airlines on this route. From the model in 3.2, as time goes by, the market share of One World on the route will be higher and higher, thus distribute the additional market share rationally and fairly related to whether the three airlines can continue maintain alliance. Shapley distribution can be a good way to solve the problem.

Introduction of Shapley distribution:

Suppose set $I=\{1,2, \ldots, n\}$, if for any subset $s$, there is a corresponding real-valued function $v(s)$ meet:

$$
\begin{aligned}
& v(\phi)=0 \\
& v\left(\boldsymbol{S}_{1} \cup \boldsymbol{S}_{2}\right) \geq v\left(\boldsymbol{S}_{1}\right)+v\left(\boldsymbol{S}_{2}\right) \quad \boldsymbol{S}_{1} \cap \boldsymbol{S}_{2}=0
\end{aligned}
$$

Here we call $[I, \mathrm{v}]$ the cooperative game of $n$ people, and $v$ is the characteristic function of game. $x_{i}$ indicates the revenue that member $i$ in $I$ achieved from the maximum cooperative benefits $v(I)$. Thus:

$$
\sum_{1}^{n} x_{i}=v(I)
$$

$x_{i} \geq v(i) \quad i=1,2, \ldots, n ;$ Shapley value distribution calls: $\Phi(v)=\left(\varphi_{1}(v), \varphi_{2}(v), \ldots \varphi_{n}(v)\right)$, for any subset $s$ calls $x(s)=\sum_{i \in s} x_{i}$, that is the distribution of each member in $s$. While all the distribution of $s$ is less than the revenue, $\boldsymbol{\varphi}_{i}(v)=\boldsymbol{x}_{i}$ is the Shapley value distribution.

$$
\boldsymbol{\varphi}_{i}(v)=\sum_{s \in S_{i}} w(|s|)[v(s)-v(s \backslash i)] \quad i=1,2, \ldots, n
$$

Here, $w(|s|)=\frac{(n-|s|) !(|s|-1) !}{n !},|s|$ indicates the element number of $s, w(|s|)$ is weighing divisor, and $s \backslash i$ is the set after $s$ divide $i$.

Suppose a period of time later, because of the competition, One World achieves a market share of $82.5 \%$ on route Hong Kong to Tokyo. Use the method above to calculate the market share of Cathay Pacific:

\section{$I=$}

$$
\begin{aligned}
& \{1,2,3\}, v(\phi)=0, v(1)=33.3 \%, v(2)=25 \%, v(3)=4.2 \% \\
& v(1,2)=78 \%, v(1,3)=39 \%, v(2,3)=32 \%, v(I)=82.5 \% \\
& \text { TABLE IV. THE CALCULATION OF MARKET SHARE OF CATHAY PACIFIC }
\end{aligned}
$$

$\begin{array}{cllll}\mathbf{s} & 1 & \{1,2\} & \{1,3\} & \mathrm{I} \\ v(s) & 33.3 \% & 78 \% & 39 \% & 82.5 \% \\ v(s \backslash 1) & 0 & 25 \% & 4.2 \% & 32 \% \\ v(s)-v(s \backslash 1) & 33.3 \% & 53 \% & 34.8 \% & 50.5 \% \\ |s| & 1 & 2 & 2 & 3 \\ w(|s|) & 1 / 3 & 1 / 6 & 1 / 6 & 1 / 3 \\ w(|s|)[v(s)-v(s \backslash i)] & 11.1 \% & 8.8 \% & 5.8 \% & 16.8 \% \\ \varphi_{(1}(v) & 42.5 \% & & & \end{array}$

The market share of Cathay Pacific is $\varphi_{1}(v)=42.5 \%$, the same, the market share of Japan airlines is $\varphi_{2}(v)=34.8 \%$, Dragon airlines $\varphi_{3}(v)=5.2 \%$.

Thus it can be seen, although the international routes market share would increase after joining aviation alliance, their individual increase depends on the airlines' strength of themselves on each route. The possible reason for the wandering international route revenue of China southern airlines after joining aviation alliance might not be reasonably adopted resources to the route that can produce great interest. While aviation alliance want to take the advantage of market on an international route, it must be reasonably allocating resources on this route, and make full use of the alliance advantages, and then gain market share, thus can bring great benefits to all joining. Meanwhile, we should pay attention to the point that the aviation alliance might not always compete with and the non-joining airlines, may be there is a competition between different alliances on the same route. And aviation alliance airlines do not have competitive advantages over all routes, thus requires the aviation alliance to evaluate all routes. Allocate the limited resources on the superior and valuable routes, thus the joining airlines can benefit more.

\section{CONCLUSION}

This paper uses a reasonable model to predict the domestic and international market of China's civil aviation after joining aviation alliance. Compared with the actual data, the prediction 
precision of the model is ideal, and the results have higher reliability. Thus not only it provides reference for China's civil aviation making policy after joining alliance, but also a theoretical support. From a practical consideration, with the increase of civil aviation transportation radices, the growth rates decreases, and each airlines should take this into consideration. From joining aviation alliance we can see, on domestic routes, airlines market increase very soon, and because of the code sharing, the domestic flights attendance will also increase. While on the international routes, because of the alliance competitive advantage, the market share of alliance airlines will continue increasing, and the Chinese airlines joining the alliance can also gain the market share. In all, joining aviation alliance is an important development opportunity for civil aviation of China.

\section{REFERENCES}

[1] Lu Jinwei Da Qingli, Lu Hongyun. The characteristics of the virtual enterprise and case analysis $[\mathrm{J}]$. Journal of engineering management.1999;13(3):4-51
[2] Xu Xuehong, Qin Rongfang Based on Petri nets virtual enterprise establish the process model [J]. Computer applications, 2001;3:7-9

[3] Chen Junhong, Wang Yingluo, Sun Linyan. The virtual enterprise partner selection process and method $[\mathrm{J}]$. The system engineering theory and practice, 2001;7:48-53

[4] Annelise.B.Virtual enterprise real[J].Telecommunication(International Edition),1998;32(4):32-36

[5] Pramord. Gupta. Optimal partner selection for virtual enterprise in agile manufacturing. [EB/OL] http:// citeseer.nj.nec.com/gupta95 optimal. html. 2001-06-05/2001-08-10

[6] Yan Qihong, Wang Chunqiang. AHP station in main traffic general layout planning in the application [J]. Journal of Southwest Jiaotong University, 1999;14(2):223-227

[7] Delgado M, Verdegay J L, Vila M A. Linguistic decision-making models[J]. Journal of Intelligent System, 1992, (7):479—492

[8] Chen C T. Extension of TOPSIS for group decision-making under fuzzy environment [J] .Fuzzy Sets and System, 2000, 114:1-9

[9] Liou T S, Wang M J. Ranking fuzzy numbers with integral value [J]. Fuzzy Sets and System, 1992, 50:247-255

[10] Kaufman A, Gupta M M. Introduction to fuzzy arithmetic:theory and applications[M]. New York:Van Norstrand Reinhold, 1985. 141-149 